\title{
健康水平平等追求與中國綱常
}

\section{倫理一一基於中國醫療衛生體制 改革進程的思考}

邊林

摘要

中國傳統網常縕含著深刻的生命道德原則, 發掘、認識和 理解這一傅統倫理文化的核心內容, 對認識和審視當代中國以 追求社會健康水準平等為目的的醫療衛生體制改革具有重要 的道德價值。如果説網常倫理是根基, 而與網常倫理一脈相承 的儒家生命倫理思想, 則能夠為認識和解決醫療衛生體制改革 的具體問題提供理論支援和邏輯分析框架。用 “差等之愛” 的 思想分析醫保籌資制度便是例證。中國醫改八年成就斐然, 社 會健康水準平等應當成為醫改的目標指向, 中國傳統網常中保 障生命安全和提供生命基本供養的思想, 能夠成為醫改的道德 原則和倫理智慧, 而儒家生命倫理學則能夠將網常倫理思想轉 化為實在的方法與路湮。

邊 林, 河北醫科大學社會科學部教授, 中國石家莊, 郵編：050017。

本文是中國國家社會科學基金專案《中國醫療衛生體制改革進程與前景的生命倫 理學審視與思考》 (13BZX090) 的階段性成果。河北省教育廳人文社會科學研究 重大課題攻關專案《醫患矛盾與衝突及處置對策研究》(ZD201426) 階段性成果。

《中外醫學哲學》XV:1 (2017 年) : 頁 19-35。

(c) Copyright 2017 by Global Scholarly Publications. 
【關鍵字】綱常倫理 健康水準平等 新醫改

中國的醫療衛生體制改革，本質上應該被認為是中國社會對 健康水準平等追求的制度設計和實踐過程, 生命道德原則應當是 這種改革的內置要素。三綱五常作為中國傳統文化的核心內容, 表面上看是等級制度社會政治統治的綱領, 本質上則藴含構築有 序社會關係的生命道德原則。把對中國的醫療衛生體制改革進程 的考察與中國傳統綱常的思想和認識聯繫起來, 並非風馬牛不相 及的拼湊。當代中國社會任何領域的變革, 都不能如同通過建構 新的醫療衛生體制而追求社會成員的健康水準平等這樣, 直接關 聯於生命原則。發掘中國傳統綱常倫理思想的生命道德價值, 將 這一思想納入儒家生命倫理思想體系, 並將其運用於對醫改的考 察和認識, 對把握醫改的方向和形成醫改的認識、理論、觀念和 思想基礎, 乃至尋求解決醫改具體問題的路徑和方法, 都不無意 義。

\section{一、健康平等與健康水準平等}

美國經濟學家安格斯 · 迪頓（Angus Deaton）在他的《逃離 不平等一健康、財富及不平等的起源》(《The Great Escape: Health, Wealth, and The Origins of Inequality》) 一書中認為, “健康水準 的不平等是財富不平等的映射” (Deaton 2015, VII)。這是迪頓研 究全球不同國家經濟發展狀況與整體健康水準關係的結論。儘管 他也認為從 “財富與健康關係” 的角度研究人類 “逃離不平等” 這一宏大問題, 是一個需要多學科共同參與的綜合性課題, 任何 一個單獨學科的研究都無法勝任。但在他看來, 因為個人或者家 庭的財富與人的健康比起來, 健康甚至比財富更重要, 所以經濟 學的視野必須擴展到對人的健康問題的關注, 同樣研究人的健康 問題, 應當與經濟學的研究結合起來, 只有深入探究財富與健康 的關係, 經濟學才可能在與生命本體關聯的意義上變得更具科學 
和道德價值。在迪頓看來, 一個國家的經濟再發達, 社會財富擁 有和積累再多, 也不會自然而然公平、合理地解決好社會成員的 健康問題; 迪頓關於財富與健康關係的這一觀點, 與另外一位經 濟學家阿馬蒂亞 · 森 (Amartya Sen) 所認為的, 一些發展中國家雖 然經濟發展水準不高, 也並非就不能在一定程度上解決社會成員 健康的基本保障問題的觀點, 能夠構成一個更完整的關於社會財 富與健康關係的認識。迪頓在書中列舉了大量的調查資料來論證 和説明這一問題。基於對全球狀況的調查和分析, 他認為目前不 僅國家之間存在著與財富不平等相關聯的健康水準的不平等，這 種不平等同樣存在於不同發展水準國家的社會群體和成員之間。

對於個體來説，健康平等與否的問題可以從兩方面去認識， 一是從社會平等意義上。一旦將個人健康平等納入社會平等意義 上去考察, 實際上個人健康平等問題就自然轉化為人口或者特定 社會群體的健康水準平等問題。這就必然帶來對這一問題另外角 度的認識, 即從生物學健康意義看所謂的個人健康平等問題, 從 這一角度看個人的健康, 根本就不存在健康平等與否的問題, 擬 或説個體健康的不平等是絕對的。世界衛生組織有理論意義上的 健康定義, 實際上每一個人都有憑藉身體和心理感受而來的對自 己健康與否的確認。生物、心理和社會適應性三個方面統一的健 康標準, 對大多數人來説, 只是一種觀念意義上的健康理想。正 因為人的健康普遍地與理想狀態存在距離, 而且這種距離並不相 等, 所以健康對個體來説不可能平等。用現有的紛繁複雜的生物 學健康標準去衡量每個人的健康狀況, 達不到標準就視為不健康 或者不夠健康, 那麼也恰恰證明人的健康不可能平等。這也就告 訴我們, 用平等概念來規定個體的健康本身是不合理的, 因為疾 病（包括心理疾病和社會適應性差）帶給個體間健康上的不平等 具有絕對性 : 疾病發生在哪個人身上是多種因素綜合作用的結 果, 預防具有改變人體某些類型疾病發病與否、發病程度的可能, 但是並不可能影響個體健康的平等問題, 任何人身上都具有發病 
的可能這一點倒是平等的, 除此之外, 從生物學意義上説, 個體 的生物性健康並不具有平等的道德規定性。如果健康對每個人來 説應該是平等的，那就等於説疾病應該發生或者不發生在某些人 或者人群身上, 或許這種情況只有在傳染性疾病的防控意義上具 有平等獲得機會、資源的道德意義, 對於個體來説, 如果在健康 上追求與他人獲得生物性的身體狀況平等, 站在生命道德的角度 看，倒是顯得不道德了。或許這就是迪頓使用健康水準平等概念 而不使用健康平等概念的原因。

健康水準平等的概念則不同,一是這種平等不是個體意義上 的，而是社會、國家或者特定群體意義上的概念，是依據一定的 標準對社會成員整體健康狀況的衡量, 比如社會慢性病發病狀 況、傳染病防控水準及防控效果評價、社會人口的整體身體素質 狀況、新生兒出生死亡率、期望壽命值的變化等。迪頓在他的書 中正是基於對不同發展水準國家的整體健康狀況的全面分析, 來 説明各個國家人口健康水準的不同，是與這個國家社會發展水準 直接相關的。二是健康水準是一個可以比較的概念, 對於社會而 言, 以社會經濟發展水準為主的多方面因素的綜合作用, 對社會 健康水準產生重要影響, 其中社會財富多寡對社會整體健康水準 影響作用最明顯, 主要是因為社會財富通過醫療衛生制度（體制） 的建構和運行, 分配給醫療衛生和社會健康保障領域一定的份 額, 醫療衛生社會建制和健康保障制度和具體的政策等, 可以直 接與社會成員實際的健康保障以及疾病的診治等關聯起來, 從而 達到為社會整體健康水準提供某種程度保障的目的。但是因為不 同國家、民族和社會的經濟發展水準、政治制度、醫療科技水準 以及醫療文化等存在巨大差異, 必然導致對影響社會整體健康水 準各種要素的觀念、體制、投入等多方面的不同，這種不同既表 現在國家之間，也表現在同一國家的不同地域之間，雖然有些方 面的差異與歷史發展或自然禀賦有關，但即便是客觀因素帶來的 對人的健康水準的影響, 也正是追求社會健康水準平等最需要解 
決的問題, 更何況社會健康水準不同人群之間的社會健康水準的 差異, 與個體健康的所謂不平等性並不具有必然聯繫。但是個體 健康狀況中的某些疾病的發病率、死亡率、轉歸率以及對特定人 群健康狀況具有重要影響的社會和自然等致病因素, 對社會健康 總體水準會有明顯甚至重要影響, 與社會健康水準有必然的聯繫。 由此可以看出, 社會健康水準平等問題的出現, 實際上是因 為太多外在於人的健康因素對健康深度影響的結果。患病個體或 者身體不健康的人與人之間無法平等, 但當這種不健康以一種社 會化的形式反映在人的整體健康水準上的時候，健康水準不平等 的問題就整體性地凸顯出來, 這種不平等的本質不是個體患者的 不健康狀況, 而是形形色色的各類疾病發生在不同的患者身上, 個體健康狀況或者患病狀況由此轉換為一個集合性或整體性的社 會健康水準狀沉, 社會如何面對、解決和提升健康水準的問題上, 就產生了健康水準平等與否的問題。

社會健康水準的不平等, 是指不同國家、不同地域或者不同 人群的健康狀況存在現實水準上的差異, 衡量這種不平等的標 準, 在技術上是關於疾病與健康的一系列指標體系, 但是這種指 標體系背後則是社會政治制度、經濟發展水準和健康文化等社會 各種要素構成的支撐體系。在迪頓看來, 如果從社會財富與社會 健康水準的關係上看待這一不平等的問題, 這種不平等源於人類 社會的發展不平衡, 因而產生了“人類發展與隨之出現的不平等 之間的複雜關聯。發展導致了不平等, 不平等卻時常有益發展, 比如為後者指明發展方向, 或者刺激後者迎頭趕上。但不平等也 時常會阻礙發展, 因為既得利益者為了維護自身地位, 會破壞追 趕者的發展道路。” (Deaton 2015，10) 社會解決健康水準不平等 問題的主要選項, 在國家內部一般是建立適合本國國情的醫療衛 生體制, 而當一個國家或者社會能夠建立起比完善的醫療衛生制 度的時候, 説明這個國家或者社會已經具備了可以承受醫療衛生 制度所能牽動和運轉的社會經濟發展水準, 在政治制度上也能夠 
基本做到“以人為本”。一個社會只有通過不斷地追求健康水準 平等, 才可能將社會發展所獲得和積累的財富真正用之於民, 因 為一個健康水準低下的國家或社會, 其他任何社會成就都會失去 根本意義, 社會成員的生命品質和不斷提升的健康水準不僅是社 會發展的根本, 也是社會發展的動力。

\section{二、“健康水準平等”應當成為“新醫改”的根本指向}

中國的“新醫改”是伴隨中國改革開放近 40 年來醫療衛生 體制一直持續不斷調整的一個嶄新階段。相對於 “新醫改”來 説, 之前的 20 多年中, “醫改” 過程始終是一個缺乏社會頂層系 統設計、伴隨社會變革而進行的一個自發調整過程, 儘管其中不 乏國家層面或前衛生部出台的種種 “改革” 意見，因為受到急劇 變化的社會多方面因素的影響, 尤其是中國社會轉型的強烈刺 激, 將中國的醫療衛生事業推上了一個行業資本化為特徵的、市 場和政府 “雙失靈” 的、道德和理性有所迷失的階段。這個階段 的明顯特徵在於種種社會性矛盾通過醫療衛生領域凸顯出來, 比 如醫療衛生的市場化在帶來行業本身總體上快速發展的同時，引 發了行業繁榮背後新的“醫療危機”，以醫院尤其是城市大型醫 院為代表的醫療衛生行業, 較快完成了資本積累和擴張, 佔有了 床位、技術、藥品、人才、設備、科研、管理等所有資源優勢, 形成了一種典型的醫療行業壟斷, 可以説這些醫院成為整個社會 醫療衛生體制運行的一個支配性乃至決定性因素, 幾乎所有與醫 藥相關的資源配置都受到它們的強烈影響。不可否認大型醫療機 構的快速擴張對推動中國社會醫療衛生事業發展的積極意義, 但 是醫療衛生行業在中國行業資本化的形成, 衍生出很多方面的社 會負性問題。這些問題集中表現為新的、多方面不平等的加劇, 這種不平等既表現在醫療行業內部, 更突出表現在對社會成員健 康水準改善的影響上, 這種影響在經濟上是有形的、顯性的, 突 出表現在看病貴以及與此相聯繫的看病難等問題上, 雖然社會健 
康的總體水準有較大的改善，但是社會成員健康水準之間並不一 定縮小了差距，也就是造就了新的健康水準的不平等。

從新中國成立到改革開放前的幾十年中, 中國社會在城鎮實 行全民公費醫療, 在農村實行合作醫療制度, 雖然是低水準甚至 可以説是極低水準, 但是基本覆蓋全體社會成員, 力求在現實中 體現無差別的平等, 但是這種平等帶有平均主義色彩, 是與高度 集權的社會經濟、政治體制相統一的一種醫療保健制度設計，追 求的是一種無差別的絕對平等。如果説從中國社會向市場經濟轉 型到 “新醫改”開始這近 20 年時間, 中國的醫療衛生領域像所有 領域一樣也是在 “摸著石頭過河”，“新醫改”是這樣摸索之後 的選擇, 但是我們應當看到, 一方面這種選擇的前期代價是巨大 的，代價之大不僅僅在於表面上 “看病難、看病貴” 等 “醫療危 機” 的加劇, 因為這個階段社會貧富差距迅速拉大, 同時醫療費 用迅速上涱, 導致在多大程度上製造了新的社會健康水準的不平 等, 被國家所提供的醫療衛生事業巨大發展成就的數字掩蓋起 來, 數字背後, 則是因這種發展模式帶來的 “逃離” 這種新的不 平等的巨大障礙。

改革開放帶來了中國社會經濟的快速發展和物質生活水準 的大幅提高, 但對於那些患者及其家屬群體來説, 高昂的醫療成 本抵消了他們的獲得感, 何況還有眾多的貧困人口和弱勢群體, 他們本來就一無所獲, 健康從來就沒有光顧過他們的生活, 健康 水準跟誰去論平等根本就無從談起。因疾病帶來的這種感受, 會 殊及到他們對社會在政治上消除貧困、追求社會公正的許諾和努 力的極大不信任。另一方面, 應當看到醫療行業運行模式上的固 化傾向, 從管理理念、職業觀念到實際利益的獲得, 無論是醫療 機構還是部分醫務人員, 都在這 20 幾年中形成和積澱了很多行業 習慣，依靠社會治理手段和制度建設來扭轉局面，建構新的醫療 體制和運行模式, 會帶來種種問題和多方面的困難, 這些困難和 
問題不是顯性的, 而是隱性的, 是與新體制建構進行抗衡的相反 力量。

應該看到，“新醫改”方案在中國實施 8 年來, 由於堅持了 “把公共衛生制度作為公共產品向全民提供” 的基本理念, 在總 方案落實過程中又先後出台了 53 個更具體化的政策性文本, 基本 涵蓋了改革方案所設計的主體內容, 在社會頂層的設計上基本形 成了新的醫療衛生體制的制度框架。而對這一框架起到強有力支 撐作用的, 是國家和地方財力上不斷加大的投入力度, 據統計, 2009 年至 2016 年全國財政醫療衛生累計支出達 6 萬億, 其中中 央財政支出累計 2 萬億, 從國家衛計委公佈的數字看, 僅 2017 年 中央財政就將投入 1.4 萬億, 超過醫改前 2008 年的 4.4 倍投入。 “十二五” 以來, 改革由試點探索、單項突破逐步轉向系統配套、 全面推進。從統計結果看, 到 2015 年底, 包括職工醫保、城鎮居 民醫保和新農合在內的全民醫保參保人數已經超過 13 億, 參保覆 蓋率穩定在 $95 \%$ 以。籌資和保障水準大幅提升, 財政補貼標準 由 2008 年的人均 80 元提高到 2016 年的 380 元。“通過深化醫改, 醫療衛生資源總量持續增加, 服務能力明顯提高, 改革紅利進一 步釋放，人民群眾健康水準顯著提高，中國居民人均預期壽命 2015年預計比 2010 年提高 1 歲; 孕產婦死亡率由 2008年的 34.2/10 萬下降到 2014 年 $27.1 / 10$ 萬, 嬰兒死亡率由 2008 年的 $14.9 \%$ 下降 至 2014 年的 $8.9 \%$ ，提前實現了 “十二五” 醫改規劃和聯合國千 年發展目標，總體上處於中高收入國家水準。（李斌 2015）雖然 國家的相關統計數字與社會部分社會成員的切身感受還有不一致 的地方, 但是這種普遍性的數字解釋還是體現著向社會健康水準 平等的方向不斷前行。

“新醫改”已經推進了 8 年時間, 從時間意義上已經不再為 “新”，但如果從社會健康水準平等意義上看, 醫改之新, 主要 表現在社會健康水準平等的推進上, 相對過去幾十年的所謂改 革, 確實已經邁出了堅實的步伐。 


\section{三、中國綱常倫理對追求社會健康水準平等的道德價值}

社會醫療衛生體制改革的根本目的，是為社會成員提供制度 和政策性的健康保障, 而是否達到了這樣的目的, 是通過社會健 康水準平等實現程度體現出來的, 或者説社會健康水準平等程 度, 可以作為檢驗醫療衛生體制合理性程度的標準。因此, 能否 真正實現健康水準平等才是醫改的最終目標。當 “平等” 概念介 入對醫改成效評價的時候, 也就意味著對醫改的評價是道德意義 上的。至少在兩層意義上, 中國的綱常倫理對認識醫改在健康水 準平等追求中的倫理價值, 可以提供道德辯護和支援。

第一層意義在於，中國傳統的綱常倫理是中國社會歷史演進 的道德根基, 同樣也是醫療衛生體制及其改革的道德根據。從一 般倫理意義上強調這一點, 有助於在醫改的進程中更多地關注傳 統道德文化對醫療公平實現的倫理價值, 同樣也是醫改追求健康 水準平等的倫理文化根據。

“三綱五常” 大致上是在兩千多年前的“周文漢制”時代基 本完成了形塑。如果以王國維的《殷周制度論》作為考察殷周時 代變革的依據，這場時代性變革，表面上看 “不過一姓一家之興 亡與都邑之轉移”，本質上則是 “舊制度廢而新制度興，舊文化 廢而新文化興”。周制是汲取了商朝亡國的教訓，“出於萬世治 安之大計”, 重建綱常, 並賦予了綱常新的內容。“德治主義”、 “民本主義” 得以張揚, 三綱之為 “民彝” 的觀念隱然出現。“五 常” 萌芽更早, 《尚書》、《左傳》都有闡釋。孔子及其所代表 的儒家是 “周文” 的傳承者, “吾從周”、“克己復禮” 等都是 最好的説明; 同時儒家也完成了思想和實踐創新。孔子的仁學思 想則是對綱常道德靈魂的深刻揭示。所有的制度、觀念、規矩等， 最終都是為了使 “天下歸仁”。“雖然還保留著社會差距, 但所 有的人都具有某種人格的平等”。“綱常” 滲透在 “周文” 數百 年的社會政治生活中, 對社會穩定發揮了重要作用。從春秋末年 的“禮崩樂壞” 開始, 到秦朝一統天下, “綱常”始終處在下行 
過程。漢立 62 年也即西元前 141 年, 開始重建綱常和制度創新的 過程，董仲舒上天人三策，提出了政治改革的綱領。“自西漢中 期之後, 主導的政治思想不再一味地加強君主集權的法家思想, 而是強調生命價值、以民為本和統治者德行的儒家思想”。這個 歷史時期, 尤其是三綱得到了比較系統的文字詮釋和理論論證, 構建為一種具有道德形而上學意味的政治倫理思想體系, 在社會 實踐中, “也作為基本的社會政治倫理原則, 成為後世兩千年傳 統社會秩序和政制的基本範型”。“中華文明和民族的數千年延 續, 其實正是靠這些綱常在社會層面維繫的, 而且, 今天我們要 重新合理地建構新的社會倫理體系, 也正是要由它們出發, 以提 供一個人們生命和財產可以得到可靠保障, 並且可以自由地發展 的社會平台”。(何懷宏 2013，7）

“三綱五常” 在中國傳統文化中的地位, 似乎是毀多於譽, 現 代中國歷史上更多是作為封建糟粕受到審視和批判。但是按照何 懷宏在《新綱常 : 探討中國社會的道德根基》一書中對儒家思想 為主導的 “綱常” 所總含的基本價值的分析, 認為儒家對綱常的 主張與法家將其作為維護政治秩序和社會統治的主張不同，其中 “還有一種更深刻、平等地看待所有生命的道德涵義。或者説， 作為綱常的綱常、綱常的核心, 其實是一種道德的原則, 這一道 德的原則主要的就是生命原則。從行為和制度規範的角度來説, 是一種要求保障生命安全和提供生命基本供養的第一正義原則; 而從價值的角度來説, 則是將生命、生存視為最寶貴的價值。而 且, 生命之所以寶貴, 並不僅是作為工具和手段的寶貴, 而是本 身就是目的的寶貴。”（何懷宏 2013，21）在儒家的思想體系中, 除了強調綱常、正名和禮教, 更為根本的是 “仁”。道德是政治 之本, 君主要以民生為本。一切從這種 “本” 出發, 儘管等級分 明, 需要服從, 但是服從因為 “本”之限制, 並非絕對, 要 “仁 者愛人”，“仁政”要以良善作為基礎。後來儒者也多有同樣的 認識和思想, “天地之生萬物也以養人, 故其可適者, 以養身體; 
其可威者, 以為容服, 禮之所為興也” (《春秋繁露·服制像》) ; “泛愛群生, 不以喜怒賞罰, 所以為仁也” (《春秋繁露·離合 根》）。儘管這種以民眾生命為上的思想的形成有其歷史原因和 局限性, 但是卻貫穿傳統社會始終, 直到傳統社會晚期, 這種保 存生命的道德原則總是構成社會等級綱常的內核。何懷宏研究認 為, “中國古典思想家的確沒有提出現代平等、自由和權利的概 念, 但是他們對生命原則的理解還是豐滿的, 包括了生命品質和 生活空間, 也包括了生存平等、人格平等和廣泛同情的觀念”。 (何懷宏 2013，26)

如果我們將中國綱常倫理納入儒家生命倫理思想體系, 來分 析它對醫療衛生體制改革的倫理價值, 不難發現, 與中國綱常倫 理思想一脈相承的儒家生命倫理理論中, “差等之愛” 的思想, 對全面地認識和解決當今醫療制度建設上的實際問題, 所具有的 價值不僅僅再是一般道德根據層面的, 而可以提供給我們具體地 認識和行為方式。這是我們所認為的綱常倫理對醫療衛生體制改 革的第二層意義。

健康水準平等是社會醫療平等的結果, 只有當醫療衛生體制 能夠體現醫療平等, 社會健康水準平等才有可能。雖然影響健康 水準平等的因素有很多, 但是具體政策制定上對如何實現醫療平 等的路徑和方法的設計, 是社會健康水準平等實現的前提。范瑞 平在他的《當代儒家生命倫理學》一書中, 對羅爾斯與儒家的平 等觀做了比較研究, 認為, 儒家 “無法接受羅爾斯關於社會正義 的一般概念, 亦即平等地對待每一個人。儒家的確認為人類生活 中有平等的一面, 平等不僅具有道德上的重要性, 而且也應該被 維持: 在儒家看來, 這種平等意味著, 每個人都值得被愛。”（范 瑞平 2011，135）但是他認為, 在儒家的倫理理論框架中, 並不 認為只有平等才具有道德上的重要性, 有些不平等同樣具有與平 等同樣的道德意義。“儒家的理論框架不僅為人類的平等, 而且 也為人類的不平等留下了足夠的空間。儘管儒家 “仁” 的原則要 
求愛人（所有的人），但是這並非要求一個道德主體要以平等或 者相似的方式去愛每一個人。相比之下, 儒學總是強調, 愛人應 當依循清晰明確的順序、區別與差異。”（范瑞平 2011，136） 這種愛有差等的思想中, 藴含著儒家對 “禮” 重視的原因, 儘管 對待不同的人可以採用不同的方式，但是 “禮” 可以作為一種制 衡的規範力量, 讓人們在不同的境況中都獲得應當得到的尊重和 有區別的愛與平等。

健康水準平等作為醫療衛生體制的終極目標，並不意味著所 有的人在這一體制下所獲得的維護自身健康的資源和所獲得健康 利益都是絕對均等的, 或者説在實現這一目標的過程中, 為此所 進行的體制改革方向的確定和具體政策的制定, 都不應該只看到 對平等追求的道德重要性，而要充分認識到“不平等”（差等） 同樣是改革所必須選擇的達到目標的方式。用以體現 “差等之 愛” 的醫療保健制度設計來作為對社會健康水準平等目標追求的 手段，恰恰體現了“平等” 與 “不平等” 的辯證關係。如果説社 會醫療衛生體制在維護健康上所有的努力是通過醫療制度體現社 會 “仁政”，是踐履儒家所強調的普遍性 “仁愛”，但是要真正 將這種 “普遍之愛” 制度化, 並能夠讓社會成員有實實在在的醫 療平等上的獲得感, 反倒不是將這種 “普遍之愛” 體現為醫療資 源配置和社會成員分配上的絕對平均主義。只有將儒家 “差等之 愛” 的倫理原則真正貫徹到醫療衛生體制設計和運行的各個環 節, 以“差等” 為前提的相對平等才是真實的、合理的。

醫療衛生體制在結構上主要包括四個方面，即醫療財政制度 (healthcare financing system 包括籌資和支付)、醫療提供制度 (healthcare delivery system)、醫療產業制度(health-related industries system)和公共健康制度(public health system)。我們僅就醫療財政 制度中的籌資這一項制度來分析，就可以看出它因為對 “差等之 愛” 的思想有所背離, 導致在籌資制度上存在道德風險。 
國家財政部有關官員強調，2017 年繼續支持提高基本醫保水 準。新農合和城鎮居民醫保財政補助標準從 2016 年每人每年 420 元提高到 2017 年的 450 元, 人均提高 30 元，這是連續第 8 年提 高財政補助標準。新農合制度是從 2003 年開始建立的, 從當時籌 資的 “三三制” 即中央財政、地方財政和個人每人每年出資 10 塊錢的標準, 14 年後的 2017 年, 總體籌資規模已經達到 630 元, 是 2003 年的 21 倍。其中, 財政補助標準由 2003 年的 20 元提高 到 450 元, 是 22.5 倍。個人繳費由 2003 年的 10 元提高到今年的 180 元, 是 18 倍。2017 年繼續支持全面推開公立醫院綜合改革。 今年整個公立醫院改革在全國全面推開, 中央財政繼續按照每個 縣補助 300 萬元, 每個新增試點城市補助 2000 萬元, 每個城市的 市轄區補助 100 萬元這樣的標準來安排補助資金, 支持在全國範 圍內全面推開公立醫院綜合改革。( 《中國新聞網》2017) 從上 述這些資料的形成不難看出, 醫改後的籌資制度和國家財政對醫 療衛生的投資制度，平均主義的“大鍋飯”傾向都十分明顯，這 種籌資和投資制度所體現出的, 確實是國家對國民的 “普遍之 愛”，但是這種制度並沒有體現出在籌資和投資上也應有的 “差 等之愛”，甚至沒有留給這種愛任何餘地。

雖然籌資管道包括個人, 但籌資後的掌控權完全在政府手 中, 這種大一統的制度設計思路, 凸顯出計劃經濟時代的絕對平 等主義傾向, 表面上看個人參與了籌資過程, 實際上政府對所籌 資金的完全掌控和通過制度所設計的分配方案, 一定程度上剝奪 了個人、家庭、企事業單位等的自主權和讓他們喪失了應負的責 任, 由此形成的“人人享有醫療衛生保健”, , 本質上帶有了平均 主義意味。如果我們承認醫療衛生體制所追求的目標是社會成員 健康水準的平等, 那麼, 如何籌集為追求這一目標而所需費用的 方式, 就要做到籌資主體結構構成多元化和多層次化。不能僅僅 依靠國家和地方財政投入作為主要籌資管道。因為社會醫療衛生 需求會伴隨生命科學技術的發展、以及藥品、診療設備的更新換 
代、疾病譜的變化等各種因素, 會對國家作為醫療衛生公共產品 的提供者提出越來越多的高要求, 總體上醫療成本會不斷上涱, 國家出資額佔財政收入之比怎樣提高，不僅不斷加重國家和地方 財政負擔, 很難滿足社會需求, 遲早難以為繼, 這已經是一些國 家的教訓。一個國家通過將醫療衛生作為公共產品提供給百姓來 體現博大的 “普遍之愛”，並不等於國家就可以不計成本地不斷 加大經濟投入，無限增加籌資額度，並以此作為 “為民” 的政績。 健康水準平等是一種比較中的平等, 是相對平等, 開放社會籌資 管道, 不僅有差別地籌資, 而且有差別地醫療消費, 支付方式與 籌資方式統一協調起來, 給商業保險、慈善事業等留足用武之地, 國家財政投入更多地關注社會弱勢群體，在政府所提供的基本醫 療保健服務的基礎上, 滿足社會成員和他們的家庭自由選擇醫療 保健服務的多層次需求。不僅讓人們能夠享受到國家的普遍之 愛, 也能享受到社會的差等之愛。

中國社會經濟、政治和文化以及環境等多方面發展的不平 衡, 也決定了醫療衛生體制的建構和改革方向, 不能建立在對每 個社會成員獲得健康利益絕對平等的追求上，同樣也需要將儒家 “愛有差等” 的思想作為醫療衛生體制下相關制度和政策內容設 計的最重要的倫理根據。

\section{四、小結}

雖經歷兩千多年社會政治、文化、道德變幺的雨雪風霜，特 別是近現代中國社會幾乎不間斷的聲討和批判的洗禮, 中國傳統 綱常始終作為中國傳統文化的核心內容, 在社會生活實踐中默默 影響著中國社會生活和發展的方面。如果按照何懷宏所認為的 “生命的道德”才是中國傳統綱常內核的認識, 包括醫療衛生體 制在內的當今中國社會所進行的所有方面的變革, 都不可能擺脱 傳統綱常所蘊含的具有本體意義的人類發展的思想和精神基礎。 而直接關涉人的生命和健康的醫療衛生體制改革, 更不能單純被 
認為是經濟活動就能徹底解決的問題, 應當提升到生命道德的高 度來審視它。這樣認識此問題的價值在於：一方面可以深刻地基 於中國傳統倫理文化來揭示醫療衛生體制改革的實質, 有利於明 確改革的指向和確立改革的方向, 發現和緊握改革的綱之所在, 讓改革的每一步都能自覺地舉綱而張目; 另一方面, 傳統綱常所 藴含的生命原則, 可以直接對接當代中國社會通過醫改對健康水 準平等的追求過程, 其當代價值可以在這一提高生命品質社會活 動的過程中得以充分彰顯和實踐運用。

研究諸如中國醫療衛生體制改革這樣的具體制度改革和建構 問題, 僅僅停留在對綱常道德價值的一般揭示上, 不能深入到對 醫療衛生體制及其改革具體問題的認識、解釋和辯護, 並不能彰 顯和體現出綱常倫理實在價值。把綱常倫理納入到儒家生命倫理 學系統, 綱常倫理所藴含的生命道德思想, 就能夠轉化為由儒家 生命倫理思想所能發揮出的對醫改具體問題的認識和解釋功能, 綱常倫理也因此更具實在的道德價值。儒家生命倫理學是一個龐 大的思想體系，僅就我們運用其中的 “差等之愛” 理論對醫改籌 資制度的分析, 就能看出這一思想對醫改所能提供的認識、解釋 乃至解決具體問題的能力和功用。

醫療衛生體制及其改革，是制度建設和政策制定的過程，其 根本問題是要解決通過醫療公平達到社會健康水準的平等。健康 水準平等的實現不是單純靠制度設計來完成的，合理制度的建構 需要思想的支撐和理論的支持。“差等之愛” 的思想，既給制度 的建構提供了思想依據, 也給制度本身預留了打破絕對平等、實 現有差別平等的道德空間。文章僅僅簡略地從對籌資制度分析中 作了闡釋, 複雜而龐大的醫療衛生體制及其改革, 如果能夠都把 儒家生命倫理思想貫徹到底, 對認識和解決改革中的難題, 或許 會提供具有中國特色的、符合中國醫療衛生實際的思想觀念和解 決問題的路徑。 
中國社會在改革開放 30 年以後, 把重新建構社會醫療衛生體 制提上議事日程, 並在 8 年的努力中取得了巨大的成就, 最近又 將“健康中國”建設提到了國策層面加以推進。表面上看，醫療 衛生體制改革是因為國家財富增加了, 全面解決中國百姓的健康 水準提高上有了一定的經濟實力, 但如果從社會政治和倫理的角 度看, 醫改是一場解決社會健康水準平等的生命道德運動。雖然 中國傳統綱常中所蘊含的關於生命道德的原則並不是基於民眾的 健康和疾病問題產生的，歷史上沒有普世制度，但有普世價值。

“我們可以説, 傳統綱常的精神與現代自由平等的價值是可以相 容的一一雖然也需要通過一定的調整和改造。即以現代社會精神 的核心——平等的觀念而論，儒家本來也就贊同人格的平等、基 本生存的平等、入仕機會的平等, 所缺的只是政治地位和參與的 平等、福利的進一步擴展等等, 而後者是可以補足而並不違背儒 家根本價值的”。

\section{參考文獻}

向玉喬: 《後現代西方倫理學研究》, 北京: 中國社會科學出版社, 2011 。 XIANG Yuqiao. Study of Postmodern Western Ethics (Beijing: China Social Sciences Press, 2013).

安格斯·迪頓 (Angus Deaton) : 《逃離不平等——健康、財富及不平等的 起源》, 北京：中信出版社, $2015 \circ$ Angus Deaton. The Great Escape: Health, Wealth, and the Origins of Inequality. Beijing: CITIC Press, 2015.

李斌: 《國務院關於深化醫藥衛生體制改革工作進展情況報告》, 中 國人大網 (www.npc.gpv.cn)，2015 年 12 月 22 日。LI Bin. Progress Report of the Ministry of Fiance on Deepening the Reform of Medical and Health Care System, The National People's Congress of the People's Republic of China, 22 December 2015. www.npc.gpv.cn.

何仁富：《生命與道德——尼采的生命道德價值論》, 北京：中國社會 科學出版社, $2013 \circ \mathrm{HE}$ Renfu. Life and Morality: Nietzsche’s Theory of Moral Values of Life (Beijing: China Social Sciences Press, 2013).

何懷宏：《新綱常：探討中國社會的道德根基》, 成都：四川人民出版 社 , $2013 \circ$ HE Huaihong. Reconstruction of Gangchang: An Inquiry into the Ethical Foundation of Contemporary China. Chengdu: Sichuan Renmin Chubanshe, 2013. 
范瑞平：《當代儒家生命倫理學》, 北京: 北京大學出版社, 2011 。Ruiping FAN. Contemporary Confucian Bioethics. Beijing: Peking University Press, 2011.

范瑞平、張穎主編：《建構中國生命倫理學：新的探索》, 北京：中國 人民大學出版社, 2017 。 Ruiping FAN, Ellen Y. ZHANG. Construction of Chinese Bioethics New Explorations (Beijing: China Renmin University Press Co., Ltd, 2017).

鄭明哲：《道德力量的來源——基於生命哲學的闡釋》, 廣州：世界圖 書出版公司廣東有限公司, 2013 。CHENG Mingche. The Sources of Moral Strength (Guangzhou: World Publishing Guangdong Corporation, 2013).

:〈財政部：2017 年全國財政醫療衛生支出預算超 1.4 萬億〉, 《中國新聞網》, http://finance.sina.com.cn，2017 年 05 月 11 日。 : Finance Office: Expenditure on Healthcare for 2017 Exceeding 1,400 Billion Budget, www.chinanews.com, 11 May 2017. http://finance.sina.com.cn. 